\section{Variability in Plant Pathogens and Tools for its Characterization}

\author{
Sunil Kumar and Shalini Verma* \\ Department of Plant Pathology, Dr. Yashwant Singh Parmar University of Horticulture and \\ Forestry, Nauni, Solan-173230 (HP), India \\ *Corresponding author
}

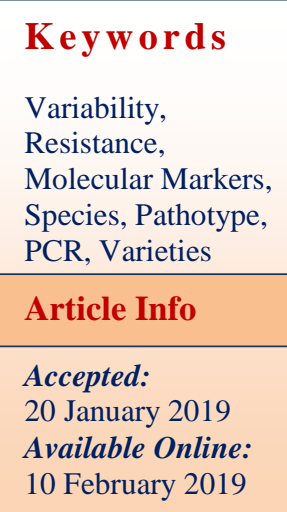

\section{Introduction}

Food losses due to crop infections from pathogens such as fungi, bacteria and viruses are major issues in agriculture at global level.

\begin{abstract}
A B S T R A C T
One of the major constraints to crop production is the biotic stress which is being caused by various fungi, bacteria and viruses. Successful management of plant disease is mainly dependent on the accurate and efficient detection of plant pathogens, amount of genetic and pathogenic variability present in pathogen population, development of resistant cultivars and deploying of effective resistance gene in different epidemiological region. In case of most of the fungal and bacterial diseases, the main reason for frequent "breakdown" of effective resistances is the variability that exists in the pathogen population, which necessitates a continual replacement of cultivars due to disease susceptibility. Mechanism of variability in case of fungi includes mutation, recombination, heterokaryosis, parasexulaism, heteroploidy and in bacteria are conjugation, transformation and transduction. Variability in viruses is generated by mechanisms of recombination, reassortment and mutation. The conventional methods for identifying the variability in the pathogens at species, subspecies and intra sub species level is being done by study of virulence reactions using disease rating scales on set of host differentials. Molecular techniques are more precise tools for differentiation between species, and identification of new strains/ isolates. Biotechnological methods can be used to characterize pathogen populations and assess the genetic variability much more accurately. Molecular methods (RAPD, RFLP, AFLP, SSR, ISSR and rDNA markers) are being used to distinguish between closely related species with few morphological differences and to distinguish strains within species. These markers can detect differences at single base pair level and has been successfully used for detection of fungi and bacteria. In future, the development of simple PCR based protocols that can be used to detect the pathogen population present in the farmers's fields. So that we can use selective breeding lines with specific resistance to a particular pathotype. These resistance (QTL) can be utilized in developing varieties and hybrid cultivar with higher levels of disease resistance.
\end{abstract} Journal homepage: http://www.ijcmas.com
In order to minimize the disease incidence in crop and to increase the productivity, advance disease detection and prevention in crop are necessary (Fang and Ramasmy, 2015). In order to assist the breeding programs the 
evaluation of genetic diversity of pathogen and its molecular characterization are crucial. Genetic analysis of pathogen populations is fundamental to understanding the mechanisms generating genetic variation, host-pathogen co-evolution, and in the management of resistance (Aradhya et al., 2001).

New pathotypes evolve with the introduction of new type of variety and hybrids to our crops. Rapid and accurate detection of new virulence will help formulate strategy for developing resistant cultivars in particular region and will also provide a base for breeding cultivars with durable resistance or designing strategies for the long term management of major diseases. Understanding the role pathogens play in shaping the genetic structure of plant populations and communities requires an understanding of the pathogens' diversity, their origins, and the evolutionary interplay that occurs between pathogens and their hosts. Here we review sources of variation that contribute to the diversity of pathogen populations and some of the mechanisms whereby this diversity is maximized and maintained.

\section{Mechanism of variability in plant pathogenic fungi}

Different pathogen develops different mechanism for generation of variability. Variability is essential for the survival of pathogen. When a new cultivar is introduced and the existing population of pathogen show avirulance to the newly introduced cultivar then pathogen have to produce variability in order survive. Plant-pathogenic fungi are diversified group of organisms with significant importance in food and agriculture sector contributing to higher yield losses annually. They intact with their hosts in number of ways. These interactions range from species that establish perennial; systemic infections which kill their hosts rapidly that form discrete lesions whose individual effects are very limited (Burdon, 1993).

\section{Migration and gene flow}

Among the major sources of genetic variation in pathogen populations, one of the major and simplest factor is gene flow although its contribution to diversity may be underestimated. Migration of one pathogen population from one place to another leads to development of new species of which are either absent or not on many occasions(e.g., the introduction of Cryphonectria parasitica to North America, Phytophthora infestans to Europe, and Puccinia striiformis to Australia.

\section{Recombination}

Recombination in plant pathogens is the similar process to that of sexual reproduction. It occurs either through a process of somatic hybridization, in which nuclear and cytoplasmic material get exchanged. In most of cases nuclear exchange may be followed by nuclear fusion and recombination also called as parasexual cycle (Fig. 3). The exchange of cytoplasmic as well as nuclear fusion leads to increased genotypic diversity in a pathogen population, but their importance varies both within and among species. In sexual reproduction ploidy level of individual get altered. Haploid gametes which are carrying a single set of chromosome fuses to form a diploid zygote with a double set of chromosomes. The gametes are formed from diploid progenitor cells by meiosis, which involves genetic recombination-the key evolutionary aspect of sexual reproduction (Schoustra et al., 2007). The role of somatic hybridization in Puccinia striiformis was reviewed by Manners. Putative recombinant races have been observed under experimental conditions. Mixtures of spores of two parental races were inoculated on a susceptible host. 
Single-spore isolates of the resulting infections were subsequently tested for their reaction on a set of differential hosts. Three single-spore isolates of a total of 30 gave virulence reactions differing from both parental races; these were interpreted as recombinants (Goddard, 1976). High diversity for both virulence and molecular markers were discovered in $P$. striiformis populations in the Chinese Gansu area and in the Middle East. However, the observation that isolates from China more readily produced telia than isolates from Europe may suggest that the large diversity in Gansu is due to sexual reproduction (Ali et al., 2010). The observations are in contrast to several studies in Europe, Australia and the Yunnan area of China, where the level of diversity was generally low and consistent with a clonal $P$. striiformis population structure. Thus, the role of recombination in $P$. striiformis may be different among regions and depend on the opportunity for sexual reproduction and/or somatic hybridization (Liu et al., 2011). Different races P.graminis f. sp.tritici having different level of virulence diversity have been originated from susceptible barberries in North America. Barberry has played a major role in generating new races of $P$. striiformis $\mathrm{f}$. sp. tritici in some regions in the world. In North American different races of stem rust, namely race $56,15 \mathrm{~B}$ and QCC, were initially originated from barberry. They were found to be responsible for generating large-scale epidemics in that area. Thus, sexual cycles on Berberis spp. may generate virulence combinations that could have serious consequences to cereal crop production (Jin, 2011).

\section{Mutation}

Gassner and Straib (1993) were the first to suggest mutation as a mechanism for formation of new races in $P$. striiformis. Mutation is a process in which there is a change in the genetic material of an organism occur either through naturally or through induced factors, which is then transmitted in a hereditary fashion to the progeny. Mutations represent changes in the sequence of bases in the DNA either through substitution of one base for another or through addition or deletion of one or many base pairs.

\section{Heterokaryosis}

Heterokaryosisis a condition in which cells of fungal hyphae or parts of hyphae contain two or more nuclei those are genetically different. For example, in Basidiomycetes, the dikaryotic state is found to be completely different from the haploid mycelium and spores of the fungus.

In $P$. graministritici, the dikaryotic mycelium can grow in both barberry and wheat but the haploid mycelium can grow only in barberry not on wheat. Similarly the haploid basidiospores can infect barberry but not wheat. However, the dikaryotic aeciospores and uredospores can infect wheat but not barberry.

Heterokaryotic condition arises by mutation, anastomosis and inclusion of dissimilar nuclei in spores after meiosis in heterothallic fungi. Cellular events preceding successful anastomosis opened the way to genetic tests on compatibility/incompatibility, which showed genetic exchange between different genotypes (Croll et al., 2009).

\section{Parasexuality}

A process in which plasmogamy, karyogamy and haploidization takes place in sequence but not at specified points in the life cycle of an individual. First discovered in 1952 by Pontecorvo and Roper in the University of Glasgow in Aspergillus nidulans, the imperfect stage of Emericella nidulans. 
The sequences of events in a complete parasexual cycle are as follow:

Formation of heterokaryotic mycelium.

Fusion between two nuclei.

Fusion between like nuclei.

Fusion between unlike nuclei.

Multiplication of diploid nuclei

Occasional mitotic crossing over during the multiplication of the diploid nuclei.

Sorting out of diploid nuclei

Occasional haploidization of diploid nuclei.

Sorting out of new haploid strains.

\section{Formation of heterokaryotic mycelium}

There are several ways in which a heterokaryotic mycelium may be formed. Anastomosis of somatic hyphae of different genetic constitutions is the most common method in which the foreign nucleus or nuclei introduced into a mycelium multiplies and its progeny spread through the mycelium, rendering the latter heterokaryotic. Another way is, in which a homokaryotic mycelium may change into heterokaryotic is by multiplication in one or more nuclei, as has been shown to occur on some ascomycetes. Third way is by the fusion of some of the nuclei and their subsequent multiplication and spread among the haploid nuclei. This would result in a mixture of haploid and diploid nuclei (Fig. 2).

\section{Karyogamy and multiplication of diploid nuclei}

When a mycelium has become heterokaryotic, nuclear fusion takes place between haploid nuclei of different genotypes as well as between nuclei of same type. The former results in a heterozygous diploid nucleus and the latter in a homozygous diploid nucleus. At this stage the mycelium may contain at least five types of nuclei. Two types of haploid, two types of homozygous diploid, heterozygous diploid nuclei. All these nuclei multiply at about same rate, but diploid nuclei are present in much smaller number then the haploidmitotic crossing over Crossing over give rise to new combinations and new linkages. It occurs not by a reduction division but by aneuploidy a phenomenon in which chromosomes are lost during mitotic division. e.g., in Penicillium chrysogenum and Aspergillus niger, the frequency of mitotic crossing over is as high as during meiosis in sexual reproduction; both lack sexual reproduction.

\section{Sorting out of diploid strains}

In the fungi which produce uninucleate conidia, sorting out of the diploid nuclei occurs by their incorporation into conidia which then germinate and produce diploid mycelia. Diploid strains of several imperfect fungi have been isolated.

\section{Haploidization}

Diploid colonies will often produce sectors which may be recognized by various methods. It produces haploid conidia which may be isolated and grown into haploid colonies. It means that some diploid nuclei undergo haploidization in the mycelium and are sorted out. Some of these haploid strains are genotypically different from either parent because of mitotic recombinations producing new linkage groups, which are sorted out in the haploid conidia.

The most plausible explanation of genetic variation in genetic makeup of karnal bunt pathogen of wheat in presence of host determinant(s) are the recombination of genetic material from two different mycelial/ sporidia through sexual mating as well as through para-sexual means. The morphological and development dependent variability further suggests that the variation in $T$. indica strains predominantly derived 
through the genetic rearrangements (Gupta et al., 2015).

In fungus A. nidulans, during somatic growth, mitotic recombination occurs at a sufficiently high rate to allow an acceleration of the adaptation to novel environmental conditions. Because fungi (unlike animals) lack a clear soma-germline distinction, nuclei with a novel recombinant genotype in the somatic tissue (the mycelium) can give rise to progeny in the form of asexual spores. The results show that recombination at the somatic level (so-called parasexual recombination) appears to be of evolutionary relevance (Schoustra et al., 2007).

\section{Mechanism of variability in Plant Pathogenic Bacteria}

\section{Bacterial conjugation}

Bacterial conjugation is the transfer of genetic material between bacteria through direct cell to cell contact, or through a bridge-like connection between the two cells. Bacterial conjugation is often incorrectly regarded as the bacterial equivalent of sexual reproduction or mating since it involves some genetic exchange. In order to perform conjugation, one of the bacteria, the donor, must play host to a conjugative or mobilizable genetic element, most often a conjugative or mobilizable plasmid or transposon (Ryan and Ray, 2004). Most conjugative plasmids have systems ensuring that the recipient cell does not already contain a similar element (Fig.4).

There are two categories of conjugative plasmids with respect to transfer: (1) selftransmissible plasmids, which encode all the genes necessary to promote cell-to-cell contact and transfer of DNA, and (2) mobilizable plasmids, which do not promote conjugation, but can be efficiently transferred when present in a cell that contains a self- transmissible plasmid. The selftransmissible plasmids are usually large. They code for 2030 proteins specifically required for bacterial cells to form a mating pair, develop a small pore, and transfer plasmid DNA through the pore from one cell to the other. The genetic information transferred is often beneficial to the recipient cell. Benefits may include antibiotic resistance, other xenobiotic tolerance, or the ability to utilize a new metabolite. Such beneficial plasmids may be considered bacterial endosymbionts. Some conjugative elements may also be viewed as genetic parasites on the bacterium, and conjugation as a mechanism that was evolved by the mobile element to spread itself into new hosts

\section{Transformation}

The uptake of naked DNA molecules and their stable maintenance in bacteria is called transformation. The phenomenon was discovered in 1928 by Griffith. Bacteria have developed highly specialized functions that will bind DNA fragments and transport them into the cell (Fig. 5).

Competence refers to the state of being able to take up exogenous DNA from the environment. There are two different forms of competence: natural and artificial. Some bacteria (around $1 \%$ of all species) are naturally capable of taking up DNA under laboratory. Such species carry sets of genes specifying the cause of the machinery for bringing DNA across the cell's membrane or membranes. Artificial competence is not encoded in the cell's genes. Instead it is induced by laboratory procedures in which cells are passively made permeable to DNA, using conditions that do not normally occur in nature (Kunik et al., 2001).

\section{Transduction}

Bacteriophages have the ability to transfer 
genes from one bacterial cell to another, a process known as transduction. There are two varieties of bacteriophage-mediated gene transfer: generalized transduction and specialized transduction (Fig. 6).

Generalized transduction occurs as a result of the lytic cycle. In the process of packaging bacteriophage DNA, the head structures of some bacteriophages will package random fragments of the bacterial chromosome. Thus, the lysate contains two kinds of particles that differ only in the kind of DNA they contain. Most of the particles contain viral DNA. When these inject their DNA, the lytic cycle will repeat and new bacteriophage particles will be produced. A small fraction of the particles, possibly as high as $1 \%$, contain fragments of the bacterial chromosome in place of the bacteriophage DNA. When one of these particles injects its DNA into the cell, the cell is not killed. The newly introduced DNA contains only bacterial genes and is free to recombine with the chromosome. Some transducing bacteriophages can introduce 100-200 kilobases of DNA. Because the bacterial fragments that are packaged are essentially random, virtually any bacterial gene of the bacterial chromosome can be transduced (hence, the term "generalized" transduction). Entire plasmids can be transduced by phages. Some plasmids, notably those encoding antibiotic resistance in staphylococci have evolved signals to allow efficient packaging by phage particles and subsequent transfer by transduction. Studies on dissemination of antibiotic resistance have revealed generalized transduction to be a significant mechanism of gene transfer in nature.

Specialized transduction requires a temperate bacteriophage. In this class of transduction, a bacterial gene becomes associated with the bacteriophage genome (e.g. by recombination). When such a bacteriophage lysogenizes a new bacterial host, it brings with it the associated bacterial gene. Because it is a bacterial gene, its expression is not turned off by the bacteriophage repressor that inhibits expression of the lytic functions. Specialized transduction leads to three possible outcomes:

DNA can be absorbed and recycled for spare parts.

The bacterial DNA can match up with a homologous DNA in the recipient cell and exchange it

$>\quad$ DNA can insert itself into the genome of the recipient cell as if still acting like virus resulting in a double copy of the bacterial genes.

\section{Mechanism of variability in Plant Viruses}

There can be many factors that facilitate the emergence of a plant virus. These include genetic mechanisms such as random mutations, recombination, reassortment, longdistance movement to new agro ecosystems, changes in vector population dynamics, and acquisition of novel virus like entities. Quite often, the emergence of a plant virus involves more than one of these mechanisms.

\section{Mutation}

The rate of spontaneous mutation is a key parameter to understanding the genetic structure of populations over time. Mutation represents the primary source of genetic variation on which natural selection and genetic drift operate. RNA viruses show mutation rates that are orders of magnitude higher than those of their DNA-based hosts and in the range of 0.03-2 per genome and replication round (Chao et al., 2002) (Fig. 1).

\section{Recombination and reassortment}

Recombination has been associated with the 
expansion of viral host range, increases in virulence, the evasion of host immunity and the evolution of resistance to antiviral. When two strains of the same virus are inoculated into the same host plant, one or more new virus strains are recovered with properties (virulence, symptomatology, etc) different from those of either of the original strains introduced into the host.

Sequence analyses of TYLCV isolates from around the world have revealed evidence of extensive recombination (Fauquet and Stanley, 2003). However, in the 1980s the incidence and severity of CMD increased markedly in East Africa (Legg, 1999; Legg and Fauquet, 2004). This was associated with the emergence of highly virulent forms via reassortment and recombination. Recombination between East African cassava mosaic virus (EACMV) and African cassava mosaic virus (ACMV), in which capsid protein $(\mathrm{CP})$ gene sequences of ACMV were exchanged with homologous sequences in EACMV, has given rise to a highly virulent recombinant (EACMV-UG2) that has been implicated in these disease outbreaks. In addition, reassortment between other recombinant EACMV components has led to the emergence of other highly virulent forms in other parts of southeast Africa (Pita et al., 2001). Together with increases in whitefly populations on cassava, these emerging viruses pose a major threat to cassava production on the African continent.

\section{Characterization of variability among pathogen population}

Successful management of plant diseases is mainly dependent on the accurate and efficient detection of plant pathogens, amount of genetic and pathogenic variability present in pathogen population, development of disease resistant cultivars and development of effective resistant gene in different epidemiological regions. Assessment of variability provides a basis of breeding cultivar with durable resistance and designing strategies for long term management of major diseases. All the disease management strategies based on host resistant require the knowledge of variability in pathogens (Sharma, 2003).

The choice of method for characterization of pathogen isolates should be based upon simplicity, reproducibility and cost effectiveness. Dynamics of pathogen variability can be used to develop resistance gene pyramiding or gene development strategies. Methods of characterization of genetic variability: traditional methods and molecular or biotechnological methods.

\section{Traditional methods}

Traditional methods used to study the variability in pathogens are based on the use of differential host, cultural and morphological markers, and study of virulence reactions using different disease rating scale on set of host differentials, biochemical tests and pigments produced by pathogen in different media.

Differential hosts are set of plant varieties used to define strains of plant pathogens based upon susceptibility or resistance reaction. Cultural characters includes colour of colony, hyphae colour conidia production etc Pathogen differ at species level with respect to their spore size, nature of conidiogenous cells, micro and macro conidia. Biochemical test involves the ability of pathogen to utilize disaccharides e.g. sucrose, maltose, lactose etc. In addition to a wide range of morphological and cultural diversity, pathogenic variability has been used to characterize the fungus at species, sub species and intra subspecies level. Isolates within one forma specialis have also been reported to 
differ in their virulence and characterized by assigning pathogenic races. Races are defined by their differential reaction on a set of host differential genotypes which may include cultivars known to carry one or more genes for resistance. Presently, eight races of Fusarium oxysporum f.sp. cicero (race 0, 1A, $1 \mathrm{~B} / \mathrm{C}, 2,3,4,5$ and 6) and five variants of Fusarium udum have been identified by reaction on a set of differential cultivars (Haware and Nene, 1982). Races 0 and1B/C induces yellowing symptoms, whereas the remaining races induce wilting. The eight races have distinct geographic distribution. Races 1-4 have been reported from India, whereas $0,1 \mathrm{~B} / \mathrm{C}, 5$ and 6 are found in the Mediterranean region and the USA. Quick induction of the disease symptoms and a standard set of host differential genotypes with known genes of resistance are the two major requirements for characterization of pathogenic diversity and identification of races. Therefore, the time consuming procedure of testing pathogenicity must be reduced by developing reliable and quick artificial inoculation and screening techniques. Also, developing a uniform and standard differential set of host genotypes based on genetic information is essential. In several cases, these are either inadequate or completely lacking and therefore, precise information on these aspects need to be generated for elucidation of the extent of pathogenic diversity present in the pathogens.

Disadvantages of conventional methods: Conventional methods distinguish pathogens on the basis of their physiological characters i.e. pathogenicity and growth behavior and can group them according to their similarity for these particular characters. However these markers are highly influenced by the host age, inoculum quality and environmental conditions. The techniques are time consuming and laborious. Moreover differential hosts are not available in most of the host- pathogen system, thus variability cannot be assessed.

\section{Molecular or biotechnological methods for characterization of variability}

Different molecular markers are used for the characterization of genetic variability in plant pathogens (Sharma et al., 1999). Molecular techniques are most precise tools for differentiation between species, and identification of new strain/ isolates collected from infected samples. The molecular methods vary with respect to discriminatory power, reproducibility, ease of use and interpretation (Lasker, 2002). DNA fingerprinting has been successfully used for Fusarium in characterization of individual isolates and grouping them into standard racial classes Lal and Dutta, 2012). This is also particularly useful when any unknown fungal sample is to be identified. Comparison at the DNA sequences level provides accurate classification of fungal species; they are beginning to elucidate the evolutionary and ecological relationships among diverse species. Molecular biology has brought many powerful new for rapid identification of isolates and methods for rapid determination of virulence or toxicity of strains.

Molecular methods have also been used to distinguish between closely related species with few morphological differences and to distinguish strains (or even specific isolates) within a species. Molecular markers monitor the variations in DNA sequences within and between the species and provide accurate identification. In recent years, different marker system such as Restriction Fragment Length Polymorphisms (RFLP), Random Amplified Polymorphic DNA (RAPD), Sequence Tagged Sites (STS), Amplified Fragment Length Polymorphisms (AFLP), Simple Sequence Repeats (SSR) or microsatellites, Single Nucleotide 
Polymorphism (SNPs) and others have been developed and applied to different fungus species. The ribosomal DNA (rDNA) based classification is also the method of choice especially when classifying the related species. The nucleotide sequence analysis of rDNA region has been widely accepted to have phylogenetic significance and is therefore useful in taxonomy and the study of phylogenetic relationships (Hibbett, 1992).

\section{Random Amplified Polymorphic DNA (RAPD)}

This is one of the simplest PCR based molecular methods available for the characterization of pathogen population. It uses random primers (Williams et al., 1990) and can be applied to any species without requiring any information about the nucleotide sequence. The amplification products from this analysis exhibit polymorphism and thus can be used as genetic markers. The presence of a RAPD band, however, does not allow distinction between hetero- and homozygous states. Genetic variability is assessed by employing short single primer of arbitrary nucleotide sequences. Specific sequence information of the organism under investigation is not required and amplification of genomic DNA is initiated at target sites which are distributed throughout the genome. Polymorphic fragments are the results of variation in the number of appropriate primer-matching sites of different DNA. Genetic similarity between isolates of $F$. oxysporum f. sp. Ciceri was studied using 40 RAPD and 2 IGS primers and results indicate that there was little genetic variability among the isolates collected from the different locations in India (Singh et al., 2006). Grajal Martin et al., (1993) assessed the variability within four races of Fusarium oxysporum $f$. sp. pisi with the help of Random amplified polymorphism DNA.

\section{Restriction Fragment Length Polymorphisms (RFLP)}

The procedures involve isolation of DNA, digestion of DNA with restriction endonucleases, size fractionation of the resulting DNA fragments by electrophoresis, DNA transfer from electrophoresis gel matrix to membrane, preparation of radiolabeled and chemiluminiscent probes, and hybridization to membrane-bound DNA. RFLP fingerprinting technique is regarded as the most sensitive method for strain identification. Direct analysis of DNA polymorphism is a more general approach to establishing genetic variation in organism. RFLP is comparatively more time consuming than PCR based methods in analyzing a large number of strains. It requires large quantities of pure DNA sample, probe preparation and fastidious procedures of Southern-blotting and hybridization. RFLP analysis of nuclear and mitochondrial DNA have been used to estimate the genetic diversity of Fusarium oxysporum (Jacobson and Gordon, 1990; Elias et al., 1993).

\section{Amplified Fragment Length Polymorphisms (AFLP)}

Amplified fragment length polymorphism (AFLP) is a variation of RAPD, able to detect restriction site polymorphisms without prior sequence knowledge using PCR amplification. AFLP analysis is one of the robust multiple-locus fingerprinting techniques among genetic marker techniques that have been evaluated for genotypic characterization. It is technically similar to restriction fragment length polymorphism analysis, except that only a subset of the fragments are displayed and the number of fragments generated can be controlled by primer extensions. The advantage of AFLP over other techniques is that multiple bands are derived from all over the genome. This 
prevents over-interpretation or misinterpretation due to point mutations or single-locus recombination, which may affect other genotypic characteristics. The main disadvantage of AFLP markers is that alleles are not easily recognized (Majer et al., 1998). AFL Panalysis offer the possibility of a broader genome coverage and its usefulness in characterizing bacterial populations was shown by Janssen et al., (1996). Its applicability to the study of Xam populations and its high discriminatory power were demonstrated by Restrepo et al., (1999b)

\section{Simple Sequence Repeats (SSR)}

Simple sequence repeats (SSR) provide a powerful tool for taxonomic and population genetic studies. This method facilitates DNA fingerprinting by the use of mini and microsatellites, which are hyper variable and dispersed DNA sequences in the form of long arrays of short tandem repeat units throughout the genome. The fragments generated by flanking primers differ in length based on the number of repeats in the amplified fragments. This length polymorphism is revealed by Agarose/ metaphor or PAGE. In the RFLP based DNA fingerprinting method di, tri and tetra nucleotide repeats have been radiolabelled and used as probes to characterize the pathogen population. However, it is different from conventional RFLP in terms of the probe used and the way the reaction is carried out. Though, the method is very precise, because of the DNA hybridization it can be laborious and time consuming. With the use of simple sequence repeats (SSR or microsatellites), (GAA)6, (GACA)4 and especially (GATA)4 high levels of polymorphism have been detected among the pathotypes. SSR offers the greatest potential for studies of comparative fitness, as multiple combinations of alleles are possible at each specific locus, thus increasing the likelihood of identifying unique test isolates for any given experiment. For tracking particular strains, or monitoring inoculum movement on a larger scale, SSR again has the greatest potential to uniquely discriminate each strain. However, further work is needed to investigate whether the resolution offered by SSRs will be sufficient in population with limited genetic diversity. DNA fingerprinting using microsatellite markers has been carried out in several plant pathogens, including the downy mildew pathogen Sclerospora graminicola (Sastry et al., 1995) and the chickpea blight pathogen Ascochyta rabei (Kaemmer et al., 1992). SSR marker distinguished the four races of Fusarium oxysporumciceri causing varied levels of wilting with differential host cultivars (Barve et al., 2001). Bogale et al.,(2005) has shown that the polymorphism revealed with 8 SSR markers was sufficient for study of genetic diversity in Fusarium oxysporum complex.

\section{Inter Simple Sequence Repeats (ISSR)}

This method is a robust, PCR based technique that produces dominant molecular-markers by DNA amplification of putative microsatellite regions (Zietkiewicz et al., 1994). ISSR markers show a higher level of polymorphism than RAPD markers (Esselman et al., 1999) and have been used extensively in other fungal population analysis (Muller et al., 1997). Intra-specific variation of ISSR products has been shown to be high in some fungal species (Hantula and Muller, 1997). The ISSR fingerprinting with four primers generates highly polymorphic markers for $F$. culmorum and proved to be authentic and reliable molecular markers for inferring the genetic relationships within and between Fusarium species (Mishra et al., 2003). 
Fig.1 Sources of gene and genotype diversity in pathogen populations (Burdon and Silk, 1997)

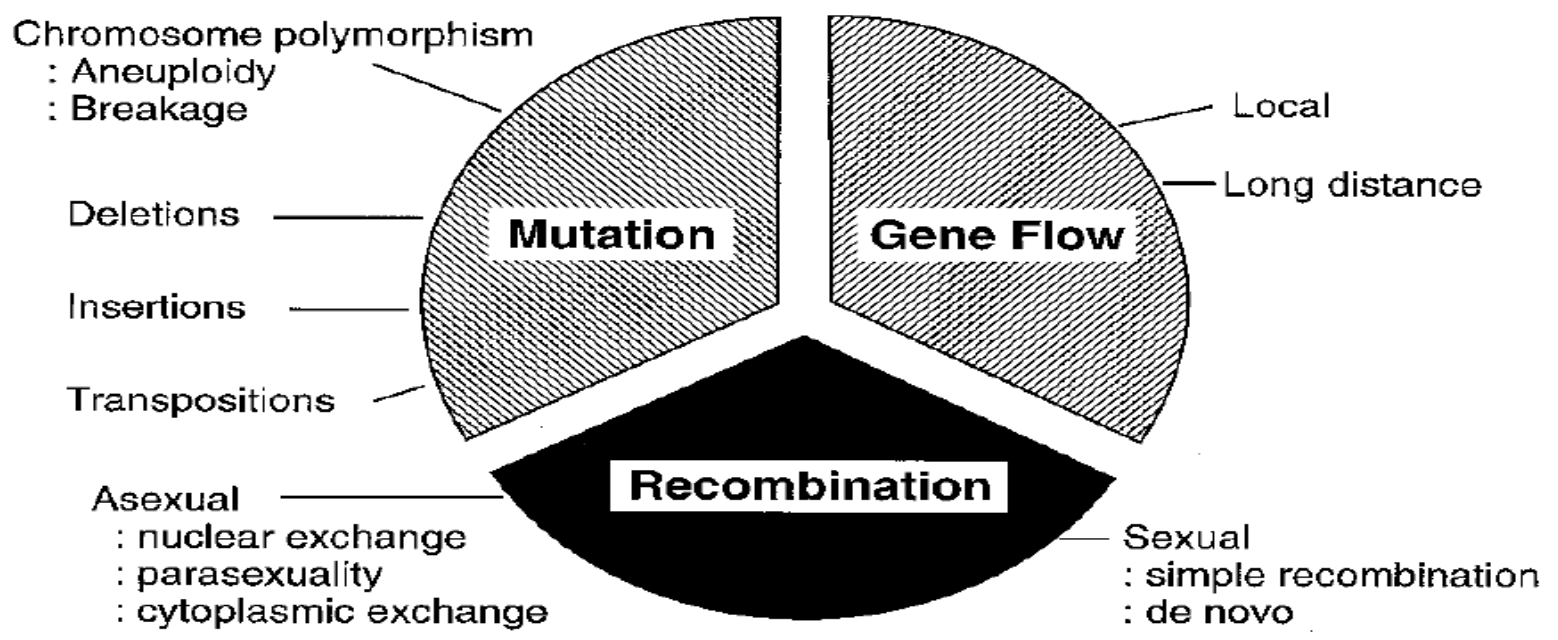

Fig.2 Perfect anastomosis formed by Funneliformis mosseae hyphae, showing nuclear mingling after staining with 2,4-diamidinophenylindole(de Novais et al., 2016)

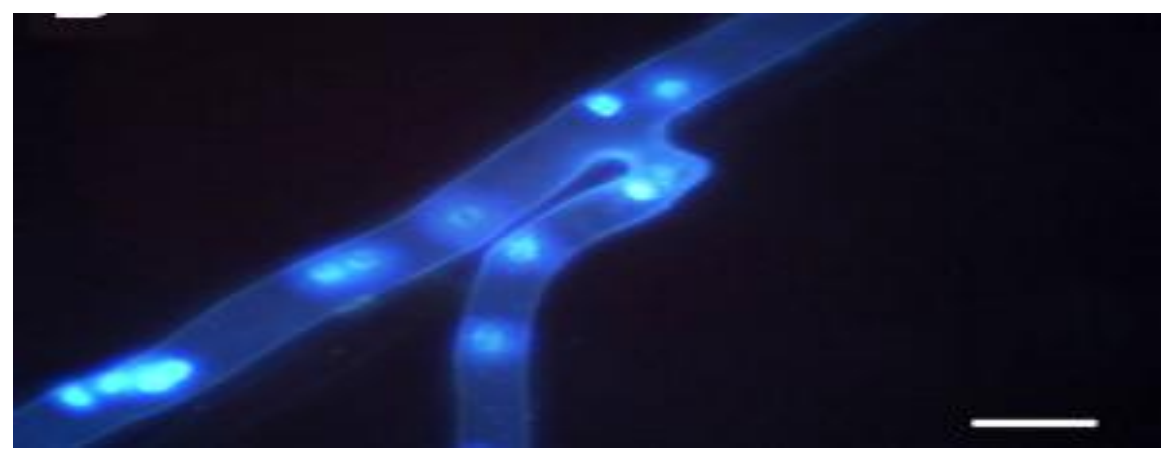

Fig.3 Schematic overview of the parasexual cycle in the filamentous fungus A. nidulans (Schoustra et al., 2007)

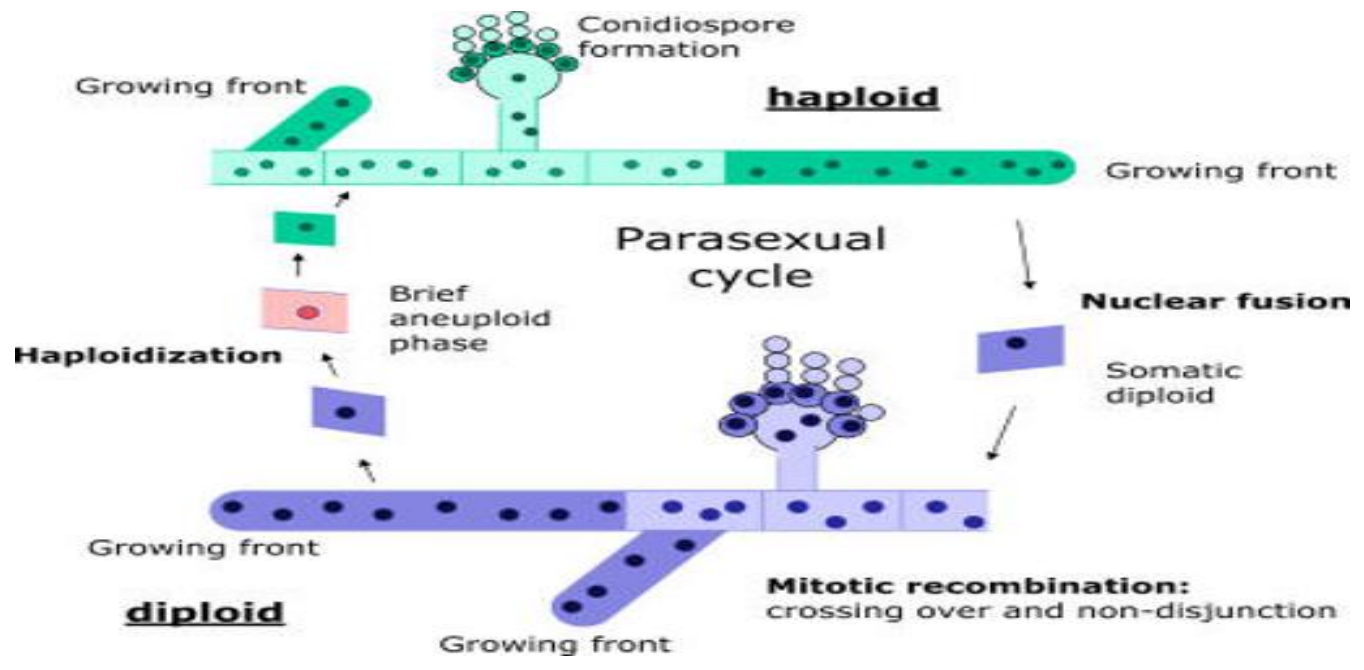


Fig.4 Conjugation between donar and parent cell (Carpa, 2010)
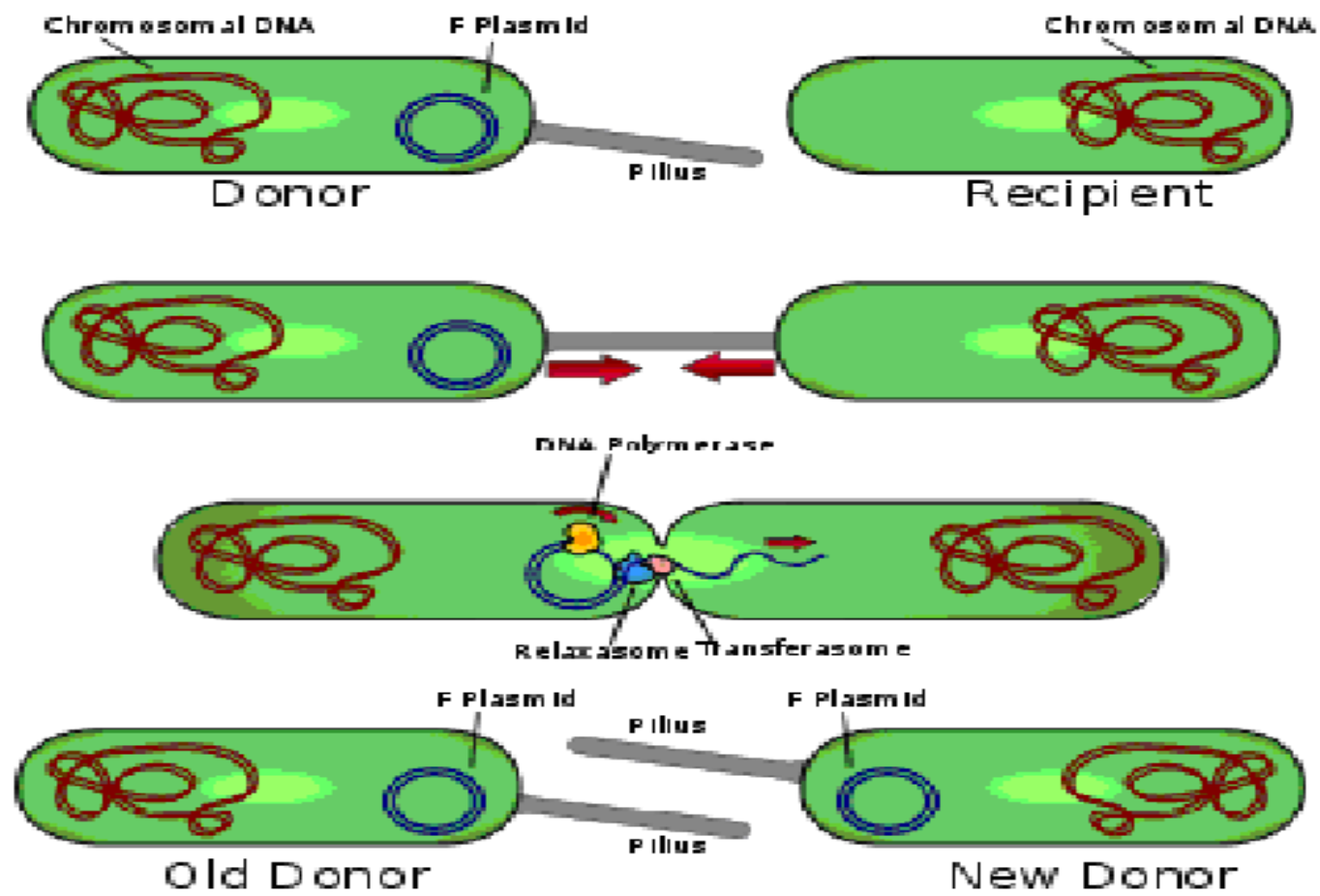

Fig.5 Transformation in bacteria (Carpa, 2010)
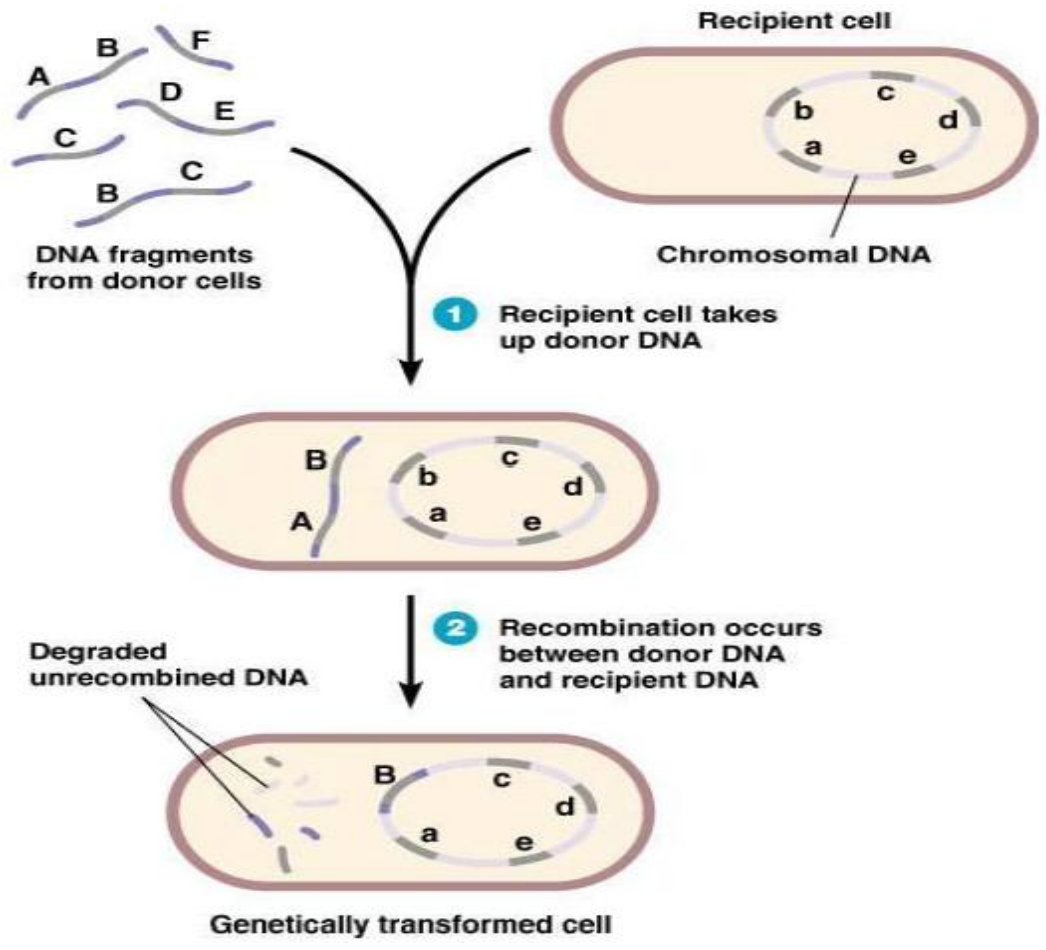
Fig.6 Specialized transduction involving donor bacterium, recipient bacterium and bacteriophage (Carpa, 2010)

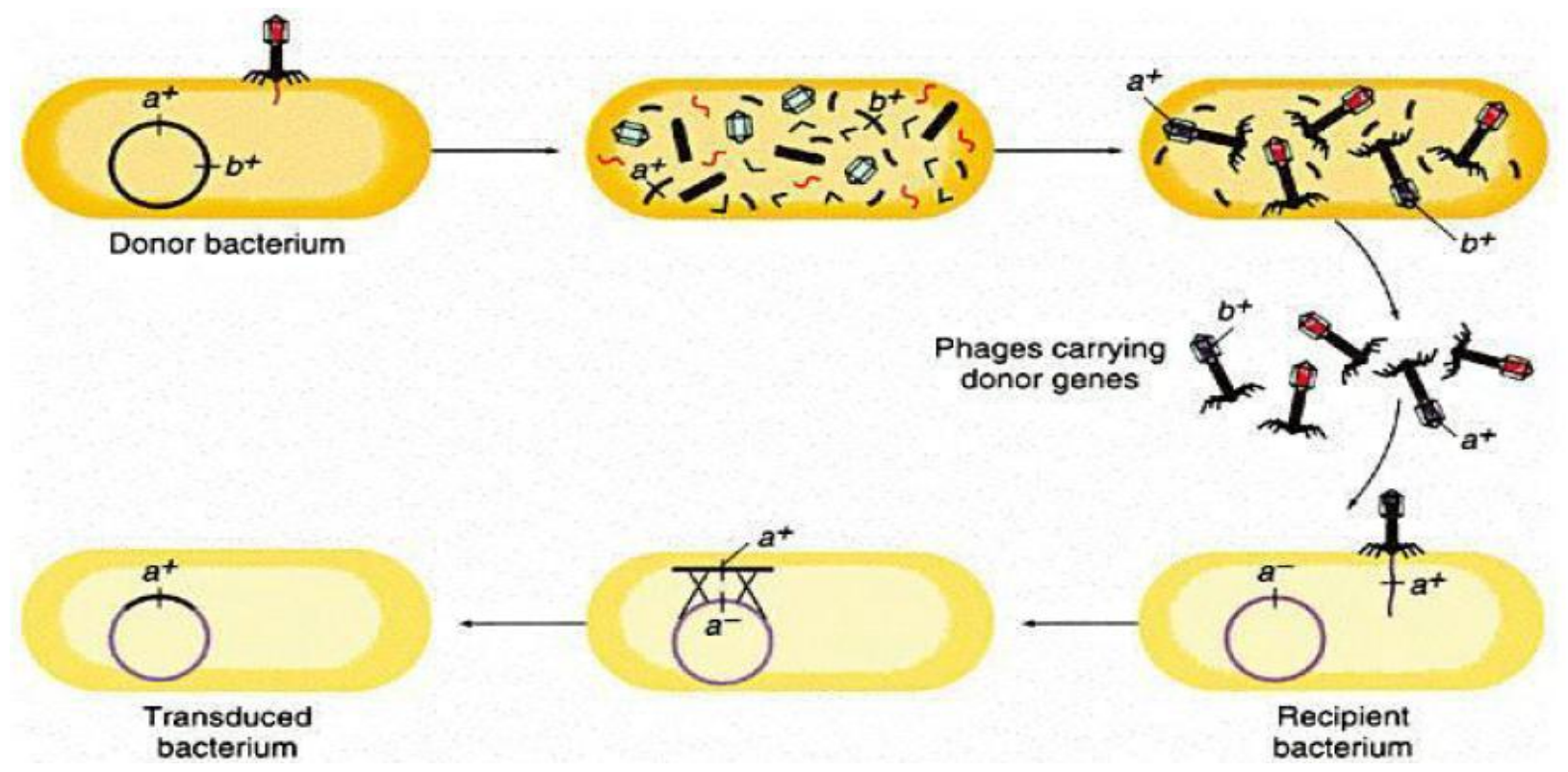

In conclusion, for breeding of resistant crop varieties, knowledge about the pathogen races in that particular crop area is very important. This is more so when the breeding objective is to provide resistance against multiple races or to pyramid several resistance genes in an elite genotype. Variability serve as survival source of pathogen. The selection pressure leads to development of the variation in pathogen which is necessary for their survival. Resistance is break down with the due course of time due to presence of variation which leads to development of virulent strains which are previously not known. General and specialized mechanisms are developed by different pathogens to produce variability. Accurate and timely detection of variability is very important form the management point of view. Both conventional and molecular methods are available for this purpose. Where conventional methods are time consuming and having higher degree of error in detection, molecular methods are more efficient, accurate and less laborious with higher degree of precession. The choice of the method for characterization of pathogen isolates should be based on simplicity, reproducibility and cost-effectiveness. The development of simple PCR based protocols that can be used to detect the pathogen population present in the farmer's fields. The complementarity of the disease resistance gene $[R]$ present in the plant and the 'avirulence' (avr) gene in the pathogen forms the basis of plant -pathogen recognition and ultimately leads to resistance or susceptibility of a plant to a specific disease. So the information on the prevalent pathotypes in a farmer's field can be made use of in selecting breeding lines with specific resistance to a particular pathotype. This resistance (QTL) can be utilized in developing varieties and hybrid cultivars with higher levels of disease resistance. This study also will lead to an understanding of the dynamics of pathogen variability that can be used to develop resistance gene pyramiding or gene deployment strategies. This will prevent selection for new virulence, which are effective against the currently available genetic sources of resistances genes. 


\section{References}

Ali, S., Leconte, M., Walker, A.S., Enjalbert, J. and de Vallavieille-Pope, C. 2010. Reduction in the sex ability of worldwide clonal populations of Puccinias triiformis f. sptritici. Fungal Genetics and Biology 47: 828-38.

Aradhya, M.K., Chan, H.M. and Parfitt, D.E. 2001. Genetic variability in the pistachio late blight fungus, Alternaria alternata. Mycological Research 105: 300-306.

Barve, M. P., Haware, M.P., Sainani, M.N., Ranjekar P.K. and Gupta, V.S. 2001. Potential of microsatellites to distinguish four races of Fusarium oxysporumf. sp. cicero prevalent in India. Theoretical and Applied Genetics 102: 138-147.

Bogale, M., Wingfield, B.D., Wingfield M.J. and Steenkamp, E.J. 2005. Simple sequence repeat markers for species in the Fusarium oxysporum complex. Molecular Ecology Notes 5: 622-624.

Burdon, J. J. 1993. The structure of pathogen populations in natural plant communities. Annual Review of Phytopathology 34: 305-323.

Burdon, J.J. and Silk, J. 1997. Sources and patterns of diversity in plant-pathogenic fungi. Phytopathology 87: 664-669.

Carpa, R. 2010. Genetic recombination in bacteria: horizon of the beginnings of sexuality in living organisms. International Journal of the Bioflux Society 2: 15-22.

Chao, L., Rang, C.U. and Wong, L.E. 2002. Distribution of spontaneous mutants and inferences about the replication mode of the RNA bacteriophage phi6.Journal of Virology 76: 3276-3281.

Croll, D., Giovannetti, M., Koch, A.M., Sbrana, C., Ehinger, M., Lammers, P.J. and Sanders, I.R. 2009. Non-self vegetative fusion and genetic exchange in the arbuscular mycorrhizal fungus Glomus intraradices. New Phytologist181: 924-937.

De Novais, C.B., Pepe, A., Siqueira, J.O., Giovannetti, M. and Sbrana, C. 2016. Compatibility and incompatibility in hyphal anastomosis of arbuscular mycorrhizal fungi. Scientia Agricola 74: 414-416.

Elias, K.S., Zamir, D., Lichtman-Pleban, T. and Katan, T. 1993. Population structure of Fusarium oxysporum $f$. $s p$. lycopersici: restriction fragment length polymorphisms provide genetic evidence that vegetative compatibility group is an indicator of evolutionary origin. Molecular Plant Microbe Interactions 6: 565-572.

Esselman, E.J., Jianqiang, L., Crawford, D.J., Windus, J.L. and Wolfe, A.D. 1999. Clonal diversity in the rare Calamogrostis porter ssp. insperata (Poaceae): Comparative results for allozymes and random amplified polymorphic DNA (RAPD) and intersimple sequence repeat (ISSR) markers. Molecular Ecology 8: 443-451.

Fauquet, C.M. and Stanley J. 2003. Geminivirus classification and nomenclature: progress and problems. Annals of Applied Biology 142:165189.

Gassner, G. and Straib, W. 1993. Uber mutationen in einerbiologischenrassevon "Puccinia glumarumtritici” (Schmidt) Erikss. and Henn. Molecular Genetics and Genomics 63:154-180.

Goddard, M.V. 1976. Cytological studies of Puccinia striiformis (yellow rust of wheat). Transactions of the British Mycological Society 66: 433-437.

Grajal, M.J., Simon, C.J. and Meuhblauer, F.J. 1993. Use of random amplified polymorphic DNA to characterize four races of Fusarium oxysporum f. sp. Pisi. 
Phytopathology 83: 612-614.

Gupta, A.K., Seneviratne, J.M., Bala, R., Jaiswal, J.P. and Kumar, A. 2015. Alteration of genetic make-up in karnal bunt pathogen (Tilletiaindica) of wheat in presence of host Determinants. Plant Pathology Journal 31:97-107.

Hantula, J. and Muller, M. 1997. Variation within Gremmeniella abietina in Finland and other countries as determined by random amplified microsatellites (RAMS). Mycological Research 101: 169-175.

Haware, M.P. and Nene, Y.L. 1982. Races of Fusarium oxysporum f. sp. ciceri. Plant Diseases 66: 809-810.

Jacobson, D.J. and Gordon, T.R. 1990. Variability of Mitochondrial DNA as an indicator of relationship between populations of Fusarium oxysporum $\mathrm{f}$. sp. melonis. Mycological Research 94: 734-744.

Janssen, P., Coopman, R., Huys, B., Swings, J., Bleeker, M., Vos, P., Zabeau M. and Kersters, K. 1996. Evaluation of the DNA fingerprinting method AFLP as a new tool to bacterial taxonomy. Microbiology 142: 1881-1893.

Jin, Y. 2011. Role of Berberis spp. as alternate hosts in generating new races of Puccinia graminis and P. striiformis. Euphytica179: 105-108.

Kaemmer, D., Ramser, J., Schon, M., Weigand, F., Saxena, M.C., Driesel, A.J., Khal G. and Weising, K. 1992. DNA fingerprinting of fungal genomes: a case study with Ascochytarabiei. Advances in Molecular Genetics 5: 225270.

Kunik, T., Tzfira, T., Kapulnik, Y., Gafni, Y., Dingwall, C. and Citovsky V. 2001. Genetic transformation of HeLa cells by Agrobacterium. Proceedings of the National Academy of Science of the United States of America 98: 18711876.
Lal, N. and Dutta, J. 2012. Progress and perceives in characterization of genetic diversity in plant pathogenic Fusarium. Plant Archives 12: 557-568.

Lasker, B.A. 2002. Evaluation of performance of four genotyping methods for studying the genetic epidemiology of Aspergillus fumigates. Journal of Clinical Microbiology 40: 2886-2892.

Legg, J.P. 1999. Emergence, spread and strategies for controlling the pandemic of cassava mosaic disease in east and central Africa. Crop Protection 18: 627637.

Legg, J.P. and Fauquet, C.M. 2004. Cassava mosaic geminiviruses in Africa. Plant Molecular Biology 56: 31-39.

Liu, X., Huang, C., Sun, Z., Liang, J., Luo, Y. and Ma, Z. 2011. Analysis of population structure of Puccinia striiformis in Yunnan Province of China by using AFLP. European Journal of Plant Pathology 129: 43-55.

Majer, D., Lewis, B.G. and Mithen, T. 1998. The use of AFLP fingerprinting for the detection of genetic variation in fungi. Plant Pathology 47: 22-28.

Mishra, P.K., Fox, R.T.V. and Chulham, A. 2003. Inter-simple sequence repeat and aggressiveness analyses revealed high genetic diversity, recombination and long range dispersal in Fusarium culmorum. Annals of Applied Biology 143: 291-301.

Pita, J.S., Fondong, V.N., Sangare, A. OtimNape, G.W., Ogwal, S. and Fauquet, C.M. 2001. Recombination, pseudorecombination and synergism of geminiviruses are determinant keys to the epidemic of severe cassava mosaic disease in Uganda. Journal of General Virology 2: 655-665.

Restrepo, S., Duque, M.C., Tohme. J. and Verdier, V. 1999. AFLP fingerprinting: an efficient technique for detecting genetic variation of Xanthomonas 
axonopodispv. manihotis. Microbiology 145: $107-114$.

Ryan, K.J. and Ray, C.G. 2004. Sherris Medical Microbiology. $4^{\text {th }}$ ed. McGraw Hill Medical. 992p.

Sastry, J.G., Ramakrishna, W., Siwaramakrishnan, S., Thakur, R.P., Gupta V.S. and Ranjekar, P.K. 1995. DNA fingerprinting detects variability in the pearl millet downy mildew pathogen (Sclerospora graminicola). Theoretical and Applied Genetics 91: 856-861.

Schoustra, S.E., Debets, A. J. M., Slakhorst, M., and Hoekstra, R. F. 2007. Mitotic Recombination Accelerates Adaptation in the Fungus Aspergillus nidulans. PLoS Genetics 3: 648-653.

Sharma, T.R. 2003. Molecular diagnosis and application of DNA markers in management of fungal and bacterial plant diseases. Indian Journal of Biotechnology 2: 99-109.

Sharma, T.R., Prachi, and Singh, B.M. 1999. Application of polymerase chain reaction in phytopathogenic microbes. Indian Journal of Microbiology 39: 7991.

Singh, B.P.R., Saikia, M., Yadav, R., Singh, V.S., Chauhan and Arora, D.K. 2006. Molecular characterization of Fusarium oxysporum f. sp. cicero causing wilt of chickpea. African Journal of Biotechnology 5: 497-502.

Zietkiewicz, E., Rafalski, A. and Labuda, D. 1994. Genome fingerprinting by simple sequence repeat (SSR) anchored polymerase chain reaction amplification. Genomics 20: 176-183.

\section{How to cite this article:}

Sunil Kumar and Shalini Verma. 2019. Variability in Plant Pathogens and Tools for its Characterization. Int.J.Curr.Microbiol.App.Sci. 8(02): 2887-2902. doi: https://doi.org/10.20546/ijcmas.2019.802.338 